\title{
Studi Optimasi Alokasi Air Pada Daerah Irigasi Bilokka Kecamatan Panca Lautang Kabupaten Sidrap Provinsi Sulawesi Selatan Menggunakan Program Linear
}

\author{
Moh. Ali Mabrur ${ }^{1 *}$, Sri Wahyuni ${ }^{1}$, Very Dermawan ${ }^{1}$ \\ ${ }^{1}$ Jurusan Teknik Pengairan, Fakultas Teknik, Universitas Brawijaya, \\ Jalan MT. Haryono No. 167, Malang, 65145, Indonesia \\ *korespondensi Email: alimabrur13579@gmail.com
}

\begin{abstract}
Bilokka Weir Irrigation is located in Panca Lautang District, Sidrap Regency, South Sulawesi Province, a potential area of \pm 1005 hectares of rice fields. Water allocation can be used to maximize agricultural productivity and profits. One of these can be overcome by optimization techniques. The optimization is intended to optimize water availability to produce maximum benefits and more effective and efficient irrigation utilization distribution. This research approach method is to the operational research mathematical programming (MP) approach, namely the Linear Program supported by the QM for Windows 4 program. From the optimization results with the MP-QM For Windows 4 program, the existing benefits of early December II planting are Rp. $21,806,950,000$ obtained a planting area of 1005 Ha at MT-I 1005 Ha and MT-II $873.5 \mathrm{Ha}$ with a planting intensity of $187 \%$ for one year. Mean while, the benefits obtained from the simulation results of the smallest discharge selected alternative three early December III planting of Rp. 23,334,010,000 obtained a planting area of 1005 at MT-I 1005 Ha and MT-II 1005 Ha with a planting intensity of 200\% for one year.
\end{abstract}

Keywords: land area, linear program, maximum profit, optimization, water allocation.

Abstrak: Irigasi Bendung Bilokka yang terletak di Kecamatan Panca Lautang Kabupaten Sidrap Provinsi Sulawesi Selatan yang memiliki luasan potensial sawah \pm 1005 Ha. Salah satu cara untuk mengatasi masalah distribusi air ialah dengan memaksimalkan produktivitas dan manfaat pertanian yang salah satunya dapat diatasi dengan salah satunya teknik optimasi. Optimasi bertujuan untuk mengoptimalkan laju pemanfaatan air irigasi agar menghasilkan manfaat yang maksimal dan penyaluran irigasi lebih efektif. Metode yang digunakan dalam penelitian ini adalah dengan menggunakan metode Mathematical Programming (MP) dari Riset Operasi yang merupakan program linier dengan dukungan program QM for Windows 4. Dari hasil teknik optimasi dengan bantuan program POM-QM For Wndows 4 maka untuk keuntungan eksisting awal tanam desember II sebesar Rp. 21.806.950.000,00 diperoleh luas tanam 1005 Ha pada MT I 1005 Ha dan MT II 873,5 Ha dengan intensitas tanam selama satu tahun sebesar 187\%, sedangkan keuntungan yang didapat dari hasil simulasi debit yang terkecil terpilihlah alternatif 3 awal tanam desember III sebesar Rp. 23.334.010.000,00 
diperoleh luas tanam 1005 pada MT I 1005 Ha dan MT II 1005 Hadengan intensitas tanam selama satu tahun sebesar $200 \%$.

Kata Kunci: alokasi air, keuntungan maksimal, luas lahan, optimasi, program linier

\section{Pendahuluan}

Irigasi Bendung Bilokka dimana terletak di Kecamatan Panca Lautang Kabupaten Sidrap Provinsi Sulawesi Selatan yang memiliki luasan potensial sawah \pm 1005 Ha. dimana ketersediaan air melimpah pada saat musim penghujan akan tetapi saat musim kemarau ketersediaan air berkurang sehingga tidak cukup untuk mengairi lahan persawahan. Sehingga produktifitas pertanian berkurang.

Salah satu caranya untuk meningkatkan hasil pertanian per satuan luas ialah dengan menyediakan air irigasi yang baik dan mengatur metode penanaman yang lebih ideal. Salah satu cara untuk mencapai tujuan tersebut adalah dengan optimalisasi pola tanam dan studi optimasi luas lahan [1]. Untuk analisis ini digunakan program linier dengan program bantu Quantitative Methods (QM) [9].

maka perlu dilakukan perencanaan pemanfaatan persediaan air dengan cermat sehingga diperoleh keuntungan yang maksimal dari ketersediaan air yang ada yang sesuai fungsinya. Salah satu cara yang dapat dilakukan untuk meningkatkan pemanfaatan air adalah dengan teknik optimasi. Optimasi merupakan suatu rancangan dalam pemecahan model-model perencanaan dengan berdasarkan pada fungsi matematika sebagai pembatas [2].

Dari penjelasan di atas maka perlu dilakukan perencanaan pemanfaatan persediaan air dengan cermat sehingga diperoleh keuntungan yang maksimal dari persediaan air yang ada yang sesuai dengan fungsinya. Salah satu cara yang dapat dilakukan untuk meningkatkan pemanfaatan air adalah dengan teknik optimasi. Optimasi merupakan suatu rancangan dalam pemecahan modelmodel perencanaan dengan berdasarkan pada fungsi matematika sebagai pembatas[10].

Tujuan penelitian ini adalah Mengetahui pola tata tanam yang efisien berdasarkan hasil optimasi dan Mempelajari manfaat keuntungan yang maksimal dari hasil pengoptimalan melalui program linier. Adapaun manfaat dari studi ini adalah Menjadikan sebagai contoh Layanan irigasi alternatif dan layanan pertanian Kecamatan Panca Lautang untuk memperbaiki jaringan irigasi dan menjadikannya lebih baik dan juga untuk meningkatkan kesejahteraan masyarakat di Daerah Irigasi Bilokka Kecamatan Panca Lautang juga bermanfaat bagi masyarakat untuk meningkatkan produksi pertanian.

\section{Bahan dan Metode}

\subsection{Bahan}

Studi ini berada pada Daerah irigasi Bllokka di Kecamatan Panca Lautang Kabupaten Sindereng Rappang Provinsi Sulawesi Selatan. Untuk kondisi lereng pada kisaran lereng $>40 \%$ sehingga peruntukannya sebagai kawasan hutan lindung. Kondisi geologi meliputi relief kasar yang merupakan morfologi perbukitan, sungai, dataran dan pegunungan. Sedangkan jenis tanah yang terdapat di kabupaten Sindereng Rappang adalah jenis Alluvial, Litosol dan Mediteran.

Kondisi hidrologi di Kabupaten Sidenreng Rappang adalah air tanah bebas (water table groundwater) sering di jumpai pada endapan alluvial dan endapan pantai. Kedalaman air tanah sangat bervariasi yang tergatung pada keadaan dan jenis lapisan batuan. 

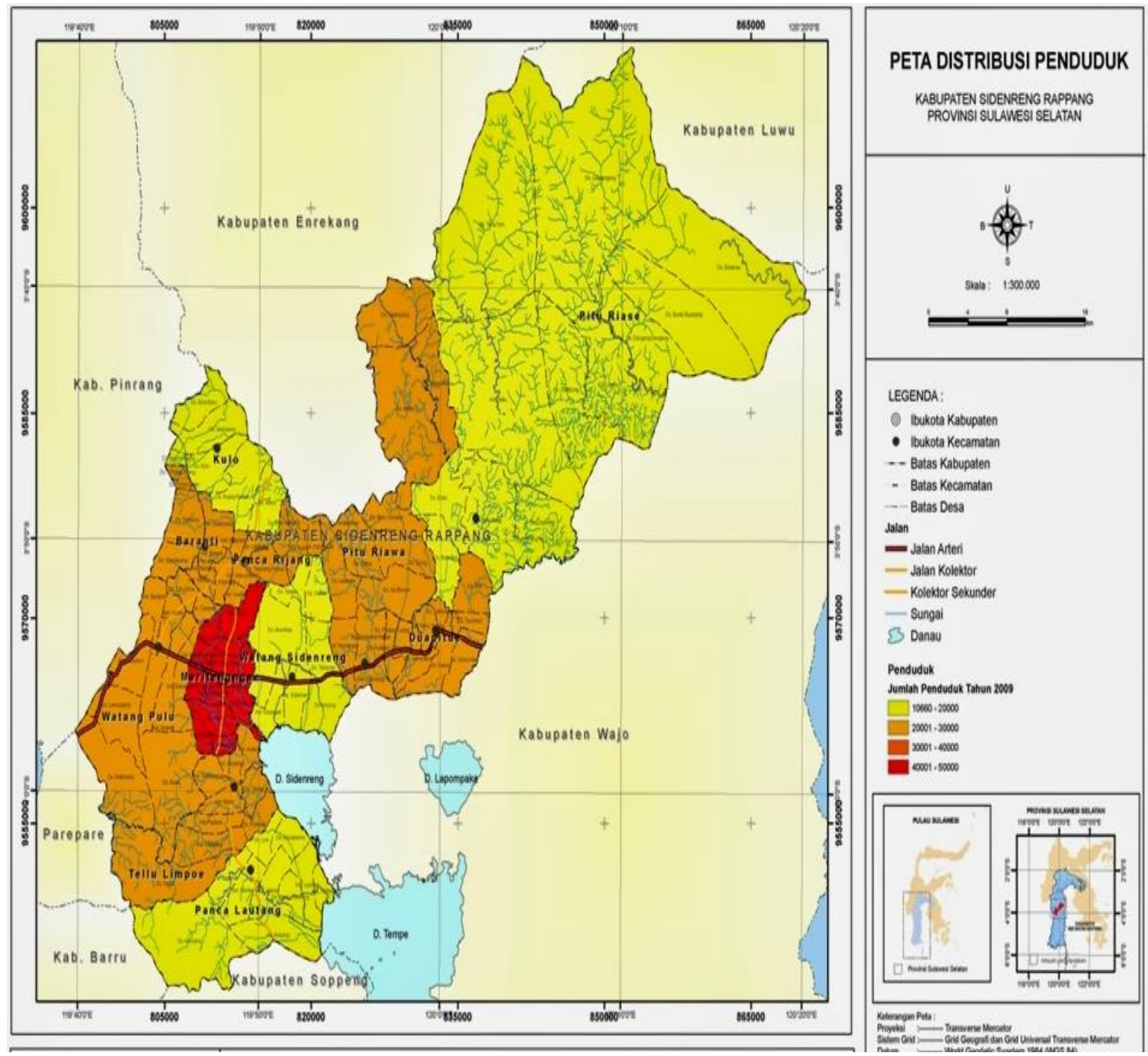

Gambar 1. Peta Lokasi Bendung Bilokka

Sumber: Hasil Penggambaran

Data-data yang diperlukan untuk analisis dalam studi ini dalah data sekunder yang dikumpulkan dari instansi terkait, yaitu:

- Data Curah Hujan; Data yang digunakan adalah data curah hujan 18 tahun (1997-2014) yang disediakan oleh Pusat Informasi Prasarana Pekerjaan Umum (BIIW) Provinsi Sulawesi Selatan.

- Data hari hujan selama 18 tahun (1997-2014) pada stasiun Amparita, stasiun Latappareng dan stasiun Salobunne yang digunakan sebagai Input dalam analisa ketersedian air diperoleh dari Balai Informasi Infrastruktur Wilayah Pekerjaan Umum Provinsi Sulawesi Selatan (BIIW).

- Data Debit; Data debit yang digunakan untuk mengetahui berapa debit andalan. Data ini di peroleh dari Dinas PU Kabupaten Sindereng Rappang.

- Data klimatologi atau iklim wilayah studi merupakan data yang diperoleh dari Pusat Informasi Infrastruktur Daerah (BIIW) di Stasiun Samberia setiap bulan. Data iklim yang digunakan meliputi data suhu, kecepatan angin, kelembaban dan radiasi matahari

- Data Pola Tanam; data realisasi tanam diperlukan untuk menyusun rencana pola tanam dan kebutuhan air. Data ini diperoleh dari Dinas PU Kabupaten Sindereng Rappang. 


\subsection{Metode}

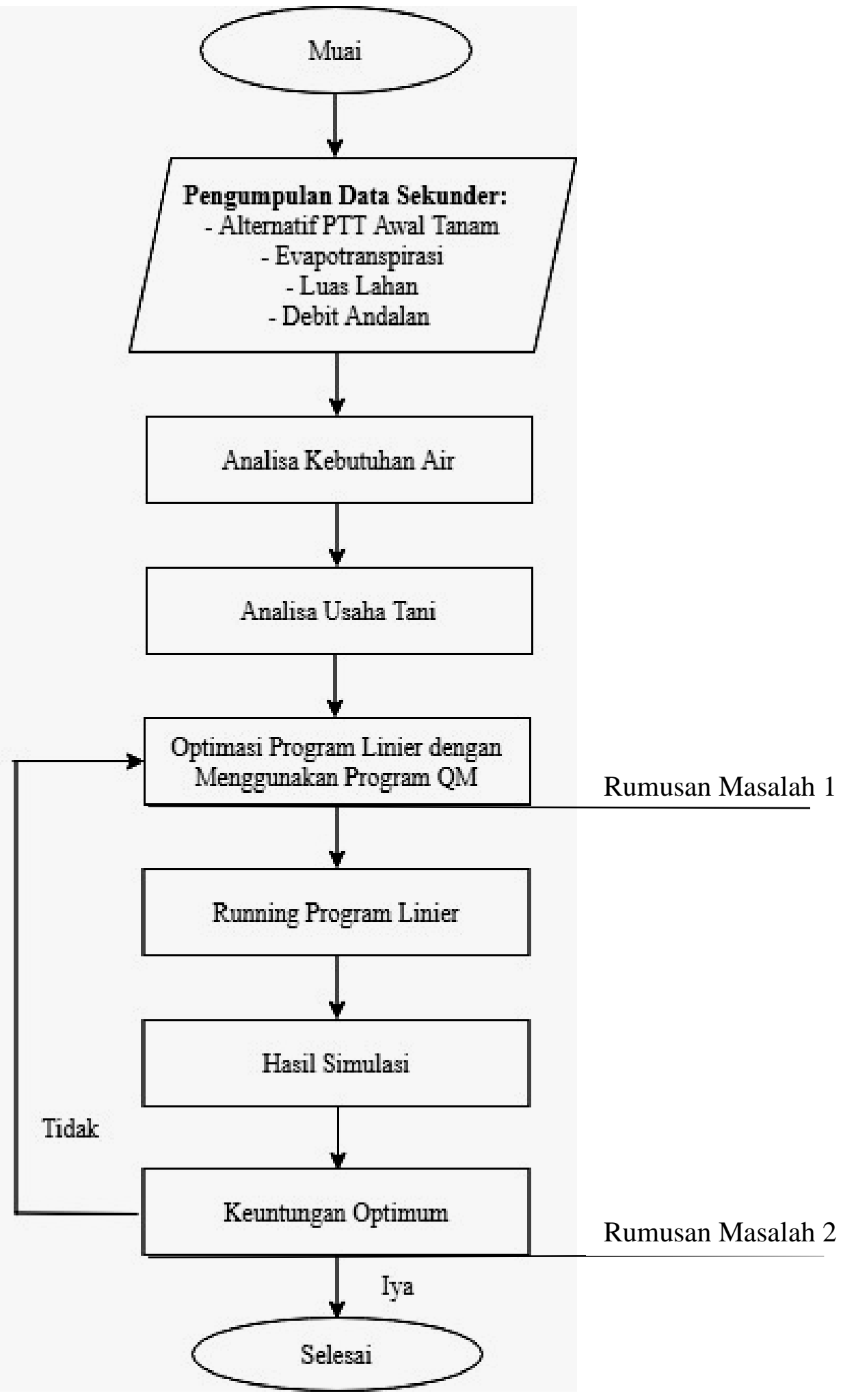

Gambar 2. Bagan Alir Pengerjaan Studi

Sumber: Hasil Penggambaran 


\subsection{Persamaan}

\section{A. Curah Hujan Andalan}

Curah hujan andalan untuk tumbuhan padi ditetapkan sebesar $80 \%$, dan untuk tumbuhan palawija sebesar 50\%. Langkah-langkah utama untuk menentukan curah hujan andalan yaitu [3]:

$$
R_{80}=\frac{n}{5}+1 \quad \text { Pers. } 1
$$

dengan:

$\mathrm{R}_{80} \quad=$ curah hujan andalan $80 \%$

n $\quad$ jumla data

\section{B. Kebutuhan Air Irigasi}

Agar terjadi keseimbangan, maka pada lahan pertanian seharusnya terjadi keadaan seimbang sebagai persamaan berikut [4]:

$$
\mathrm{IR}=(\mathrm{ETc}+\mathrm{Pd}+\mathrm{P} \& I)-R e \quad \text { Pers. } 2
$$

\begin{tabular}{|c|c|}
\hline IR & $=$ Kebutuhan air irigasi (lt/dt/ha) \\
\hline $\operatorname{Re}$ & $=$ besarnya curah hujan efektif $(\mathrm{mm} / \mathrm{hr})$ \\
\hline Etc & $=$ keperluan air tanah tumbuhan $(\mathrm{mm} / \mathrm{hr})$ \\
\hline $\mathrm{Pd}$ & $=$ keperluan air pengolahan tanah $(\mathrm{mm} / \mathrm{hr})$ \\
\hline P\&I & $=$ perkolasi dan infiltrasi $(\mathrm{mm} / \mathrm{hr})$ \\
\hline
\end{tabular}

\section{Penyiapan Lahan}

Persamaan penyiapan lahan dapat dihitung dengan rumus [5]:

dengan:

$$
\mathrm{Lp}=\mathrm{M} . \mathrm{e}^{\mathrm{k}} /(\mathrm{ek}-1) \quad \text { Pers. } 3
$$

LP $\quad=$ Keperluan air irigasi ditingkat pertanian $(\mathrm{mm} / \mathrm{hari})$

$\mathrm{M}=$ Keperluan air untuk mengganti kehilangan air akibat evaporasi dan perkolasi

$$
\mathrm{M}=\mathrm{Eo}+\mathrm{P} \quad \text { Pers. } 4
$$

Dengan:

E $\quad=$ Evaporasi air terbuka yang diambil 1,1 ETo selama Penyiapan lahan $(\mathrm{mm} / \mathrm{hari})$ $\mathrm{P} \quad=$ perkolasi $(\mathrm{mm} / \mathrm{hari})$

dengan:

$$
\mathrm{K}=\mathrm{M} . \mathrm{T} / \mathrm{S} \quad \text { Pers. } 5
$$

$\mathrm{T}=$ Waktu penyiapan lahan (hari)

$\mathrm{S}=$ Keperluan air, untuk penjenuhan di tambah dengan lapisan air $50 \mathrm{~mm}$

\section{Evaporasi}

\begin{tabular}{|c|c|}
\hline Eto & $=$ Evapotranspirasi potensial $(\mathrm{mm} / \mathrm{hari})$ \\
\hline W & $=$ Nilai factor \\
\hline Rs & $=$ Radiasi gelombang pendek \\
\hline $\mathrm{Fu}$ & $=$ Nilai fungsi angin \\
\hline $\mathrm{Ea}$ & $=$ Tekanan uap jenuh \\
\hline Ed & $=$ Tekanan uap nyata \\
\hline
\end{tabular}

Dalam studi perhitungan besarnya evaporasi dapat dipakai rumus empiris Penman, dengan menggunakan rumus (FAO, Roma 1977) pada persamaan sebagai berikut [3]: dengan:

$$
\text { Eto }=(W) \times((0,75 \times R s)-R n 1)+((1-W) \times f u \times(e a-e d)) \quad \text { Pers. } 6
$$




\section{E. Program Linier}

Metode simpleks mengiterasi banyak persamaan yang mewakili fungsi tujuan dan fungsi batas dalam program linier [2], dan persamaan ini telah disesuaikan dengan bentuk standarnya. Di bawah ini, bentuk standar dari persamaan simpleks diberikan [6]:

dengan:

$$
\mathrm{Za}=\mathrm{A} . \mathrm{X} 1+\mathrm{A} . \mathrm{X} 2 \quad \text { Pers. } 7
$$

Za $\quad=$ Nilai target yang ingin dicapai dalam Rp (memaksimalkan keuntungan)

A $\quad=$ Pendapatan dari produksi padi $(\mathrm{Rp} / \mathrm{ha})$

$\mathrm{X} 1=$ Areal produksi MT. 1 (ha)

$\mathrm{X} 1=$ Areal produksi MT. 2 (ha)

\section{Hasil dan Pembahasan}

\subsection{Debit Andalan}

Debit pokok menghitung kemungkinan menggunakan $80 \%$. Nilai emisi yang dapat diandalkan tertinggi diperoleh pada bulan Mei yaitu 2,073 m3 / s. Pada saat yang sama, volume emisi yang dapat diandalkan terendah adalah $0,145 \mathrm{~m} 3 / \mathrm{dt}$ di bulan Oktober.

\subsection{Perhitungan Kebutuhan Air Irigasi}

Untuk menghitung kebutuhan air irigasi perlu dipahami metode tanam yang digunakan, seperti terlihat pada Tabel 1 .

Tabel 1. Pola Tanam Eksisting dan Alternatif

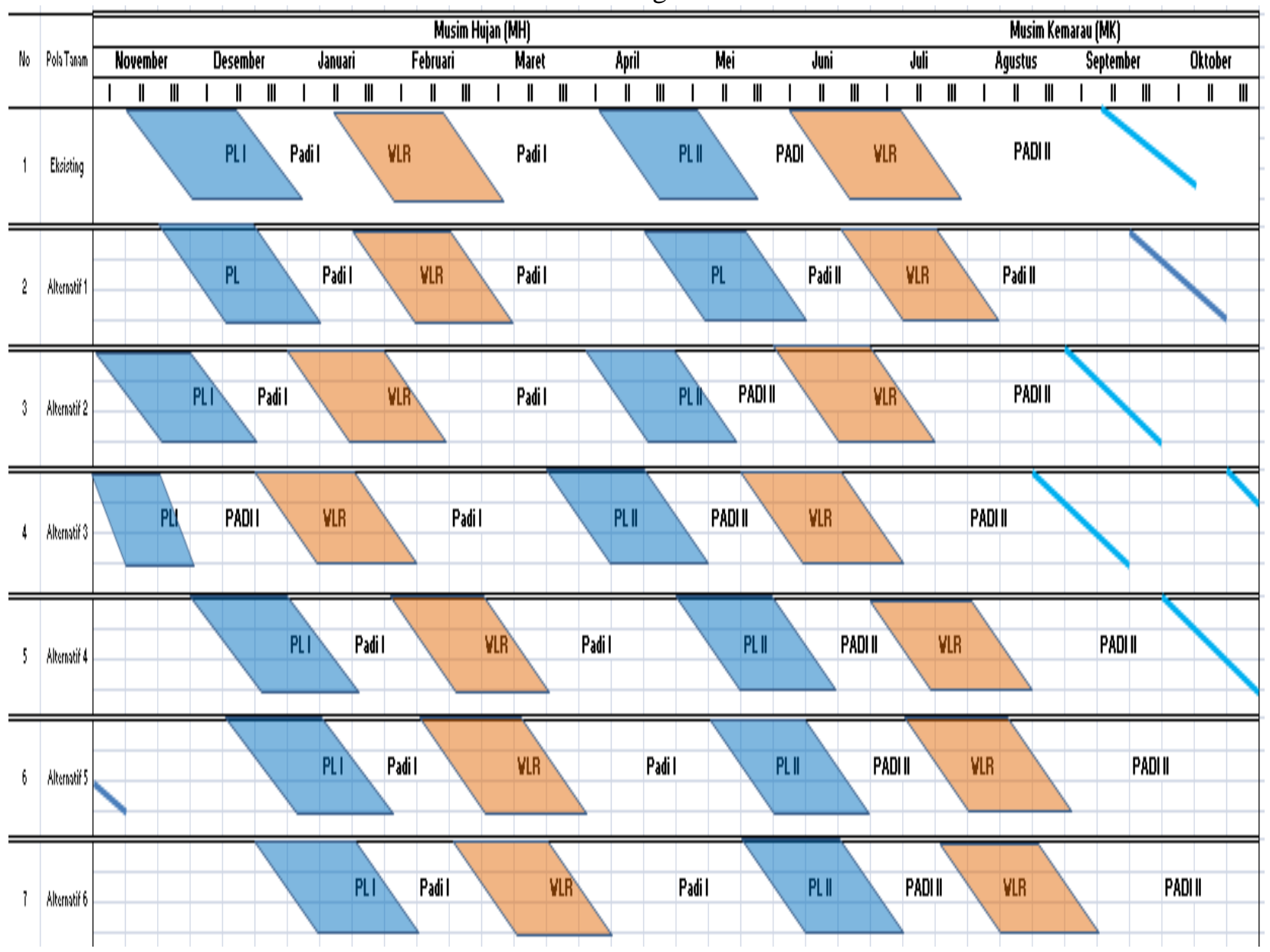

Sumber: Hasil Perhitungan 


\subsection{Volume Kebutuhan Air Irigasi}

Tabel 2 mencantumkan ringkasan hasil kebutuhan air irigasi:

Tabel 2. Kebutuhan Air Irigasi

\begin{tabular}{|c|c|c|c|}
\hline \multirow[t]{2}{*}{ no } & \multirow[t]{2}{*}{$\begin{array}{l}\text { Pola Tanam Daerah } \\
\text { Irigasi Bilokka }\end{array}$} & \multirow[t]{2}{*}{ Musim Tanam } & $\begin{array}{l}\text { Kebutuhan Air Irigasi } \\
\text { (m3/ha) }\end{array}$ \\
\hline & & & Padi \\
\hline \multirow{2}{*}{1} & \multirow{2}{*}{ PTT Eksisting } & MT. 1 & 16073,20 \\
\hline & & MT. 2 & 12211,48 \\
\hline \multirow{2}{*}{2} & \multirow{2}{*}{ PTT Alternatif 1} & MT. 1 & 15338,88 \\
\hline & & MT. 2 & 11703,68 \\
\hline \multirow{2}{*}{3} & \multirow{2}{*}{ PTT Alternatif 2} & MT. 1 & 16142,24 \\
\hline & & MT. 2 & 11799,67 \\
\hline \multirow{2}{*}{4} & \multirow{2}{*}{ PTT Alternatif 3} & MT. 1 & 16812,32 \\
\hline & & MT. 2 & 11123,82 \\
\hline \multirow{2}{*}{5} & \multirow{2}{*}{ PTT Alternatif 4} & MT. 1 & 15774,46 \\
\hline & & MT. 2 & 13619,62 \\
\hline \multirow{2}{*}{6} & \multirow{2}{*}{ PTT Alternatif 5} & MT. 1 & 15687,62 \\
\hline & & MT. 2 & 14434,43 \\
\hline \multirow{2}{*}{7} & \multirow{2}{*}{ PTT Alternatif 6} & MT. 1 & 15560,31 \\
\hline & & MT. 2 & 14502,23 \\
\hline
\end{tabular}

Sumber: Hasil Perhitungan

\subsection{Volume Kebutuhan Air irigasi}

Tiap -tiap pola tata tanam ke mudian dianalisa kebutuhan air irigasinya. Hasil rekapitulasi dari kebutuhan air irigasi dapat dilihat pada Tabel 3.

Tabel 3. Kebutuhan Air irigasi

\begin{tabular}{|c|c|c|c|}
\hline \multirow[t]{2}{*}{ no } & \multirow[t]{2}{*}{$\begin{array}{l}\text { Pola Tanam Daerah } \\
\text { Irigasi Bilokka }\end{array}$} & \multirow[t]{2}{*}{ Musim Tanam } & $\begin{array}{l}\text { Kebutuhan Air Irigasi } \\
\text { (m3/ha) }\end{array}$ \\
\hline & & & Padi \\
\hline \multirow{2}{*}{1} & \multirow{2}{*}{ PTT Eksisting } & MT. 1 & 16073,20 \\
\hline & & MT. 2 & 12211,48 \\
\hline \multirow{2}{*}{2} & \multirow{2}{*}{ PTT Alternatif 1} & MT. 1 & 15338,88 \\
\hline & & MT. 2 & 11703,68 \\
\hline \multirow{2}{*}{3} & \multirow{2}{*}{ PTT Alternatif 2} & MT. 1 & 16142,24 \\
\hline & & MT. 2 & 11799,67 \\
\hline \multirow{2}{*}{4} & \multirow{2}{*}{ PTT Alternatif 3} & MT. 1 & 16812,32 \\
\hline & & MT. 2 & 11123,82 \\
\hline \multirow{2}{*}{5} & \multirow{2}{*}{ PTT Alternatif 4} & MT. 1 & 15774,46 \\
\hline & & MT. 2 & 13619,62 \\
\hline \multirow{2}{*}{6} & \multirow{2}{*}{ PTT Alternatif 5} & MT. 1 & 15687,62 \\
\hline & & MT. 2 & 14434,43 \\
\hline \multirow{2}{*}{7} & \multirow{2}{*}{ PTT Alternatif 6} & MT. 1 & 15560,31 \\
\hline & & MT. 2 & 14502,23 \\
\hline
\end{tabular}

Sumber: Hasil Perhitungan 


\subsection{Volume Andalan}

Jumlah yang dapat diandalkan merupakan nilai air irigasi dan akan digunakan sebagai fungsi pembatas / pembatas dalam penelitian ini.

Tabel 4. Volume Andalan

\begin{tabular}{|c|c|c|}
\hline \multirow{2}{*}{ No } & \multicolumn{2}{|c|}{ VOLUME ANDALAN $\left(\mathrm{m}^{3}\right)$} \\
\cline { 2 - 3 } & MT1 & MT2 \\
\hline Eksisting & 26,153 & 12,244 \\
\hline Alternatif 1 & 26,237 & 16,387 \\
\hline Alternatif 2 & 26,070 & 14,172 \\
\hline Alternatif 3 & 25,736 & 16,096 \\
\hline Alternatif 4 & 26,320 & 8,388 \\
\hline Alternatif 5 & 30,080 & 8,098 \\
\hline Alternatif 6 & 27,488 & 7,809 \\
\hline
\end{tabular}

Sumber: Hasil Perhitungan

\subsection{Analisa Usaha Tani}

Analisis hasil pertanian merupakan hasil pendapatan bersih petani yang diperoleh dengan cara mengurangkan biaya produksi petani per hektar dari total pendapatan mereka [7]. Karena keterbatasan data analisa usaha tani maka dalam penelitian ini, Analisis usahatani yang digunakan adalah data dari 2 kecamatan di Kabupaten Sidenreng Rappang, yaitu di Kecamatan Pitu Raise dan Kecamatan Pitu Riawa [8]. Berikut ini adalah pendapatan bersih petani yang dihitung berdasarkan data rata-rata analisis usahatani pada Tabel 5.

Tabel 5. Perhitungan pendapatan berih Petani Dibilokka per Hektar

\begin{tabular}{|c|c|c|c|c|c|c|}
\hline \multirow{2}{*}{ Jenis Tanaman } & \multicolumn{4}{|c|}{ Kecamatan } & \multirow{2}{*}{\multicolumn{2}{|c|}{ Rerata }} \\
\hline & & tu Riase & & u Riawa & & \\
\hline Padi Tiwi & $\mathrm{Rp}$ & 9.593 .297 & $\mathrm{Rp}$ & 13.624 .627 & $\mathrm{Rp}$ & 11.608 .962 \\
\hline \multicolumn{5}{|c|}{ Total } & $\mathrm{Rp}$ & 11.608 .962 \\
\hline \multicolumn{5}{|c|}{ Total Pendapatan di DI Bilokka } & $\mathrm{Rp}$ & 11.667 .006 .810 \\
\hline
\end{tabular}

Sumber: Ma'ruf (2019) dan Hasa (2018)

\subsection{Model Matematika Optimasi}

Penelitian ini menggunakan dua alternatif optimasi, yaitu:

1. Menentukan pola tata tanam yang paling efesien dari hasil optimasi.

2. Memaksimalka keuntungan pola tata tanam alternatif dengan program bantu Quantitative Methods $(Q M)$.

Skema optimasi yang digunakan adalah sebagai berikut:

\section{Fungsi Tujuan dan Batasan}

\section{a. Tujuan}


Rumus fungsi tujuan adalah sebagai berikut:

$\mathrm{Z}=\mathrm{A} \cdot \mathrm{X} 1+\mathrm{A} \cdot \mathrm{X} 2$

Dengan:

$\mathrm{Z}=$ = Nilai tujuan (keuntungan maksimal) yang ingin dicapai $\mathrm{Rp}$

$\mathrm{A} \quad=$ Pendapatan dari produksi padi $(\mathrm{Rp} / \mathrm{ha})$

$\mathrm{X} 1=$ Luas tanam padi MT. 1 (ha)

X2 = Luas tanam padi MT. 2 (ha)

b. Fungsi Batasan

i. Luas Maksimum

$\mathrm{X} 1 \leq \mathrm{Xt}$

$\mathrm{X} 2 \leq \mathrm{Xt}$

Dengan:

$\mathrm{Xt}=$ Luas keseluruhan DI Bilokka (1005 ha)

ii. Volume Air yang Tersedia

V1p.X1 $\leq$ V1s

V2p.X2 $\leq$ V2s

Dengan:

V1p = Keperluan air padi tiap MT. $1\left(\mathrm{~m}^{3} / \mathrm{ha}\right)$

V2p $=$ Keperluan air padi tiap MT. $\left.2\left(\mathrm{~m}^{3} / \mathrm{ha}\right)\right)$

V1s = Volume andalah sungai pada MT. $1\left(\mathrm{~m}^{3}\right)$

V2s = Volume andalah sungai pada MT. $2\left(\mathrm{~m}^{3}\right)$

iii. Kapasitas Intake Bendung

V1p.X1 $\leq \mathrm{Qb}$

V2p.X2 $\leq \mathrm{Qb}$

Dengan:

$\mathrm{Qb}=$ Kapasitas intake bendung bilokka

\subsection{Rekapitulasi Nilai Optimum}

\section{Neraca Air}

Nilai neraca air diperoleh dengan membandingkan aliran utama dan aliran yang tersedia untuk irigasi. Perbedaan nilai minimum air untuk areal eksisting seluas 1005 hektar kemungkinan disebabkan oleh pola usahatani yang ada yaitu $12.244 \mathrm{~m} 3 / \mathrm{dt}$. Sedangkan untuk luas yang terpilih yaitu alternative 3 dengan luas 1005 ha, selisih nilai terkecil yaitu sebesar 16,069 m³/dt.

\section{Intensitas Tanaman}

Nilai intensitas tanaman dinyatakan sebagai persentase dari setiap musim tanam dalam setahun.

Intensitas tanam dari pola tanam eksisting dan luas tanam saat ini dari model tanam Alternatif 2 dari Alternatif 6 adalah 873,5 hektar yaitu 187\%, dan kerapatan hasil dari Alternatif 4 adalah $153 \%$.

Untuk luas alternative yang terpilih 1005 ha, hasil intensitas tanaman pada pola tanam alternatif 3 adalah sebesar 200\%. Sementara untuk pola tanam alterntif 1 dan 2 sebesar 200\%, alternative 5 sebesar $148 \%$ dan alternative 6 adalah $146 \%$. 


\section{Keuntungan Hasil Pertanian}

Nilai keuntungan hasil pertanian dinyatakan dalam rupiah setahun. Nilai maksimum eksisting terdapat pada model tanam eksisting dengan keuntungan sebesar Rp. 21.806.950.000. Untuk sementara alternative yang terpilih yaitu alternative 3 dengan luas 1005 ha, keuntungan maksimum diperoleh sebesar Rp. 23.334.010.000.

\section{Kesimpulan}

Berdasarkan hasil perhitungan dan analisis data yang telah dilakukan maka dapat diambil kesimpulan sebagai berikut:

1. Pola tata tanam yang paling efisien dari hasil optimasi adalah Padi 1 (MT1) - Padi II (MT2). Awal tanam yang paling efisien dimulai pada November III dengan debit kebutuhan yang paling kecil (jika dibandingkan dengan alternatif lain) yaitu sebesar 1,564 liter/detik/ha. Dan volume ketersediaan pada saat musim tanam 1 yaitu sebesar $22.235 .900 \mathrm{~m}^{3}$, untuk musim tanam 2 sebesar $13.907 .370 \mathrm{~m}^{3}$. Sehingga total volume ketersediaan selama 2 musim tanam adalah sebesar $36.143 .270 \mathrm{~m}^{3}$

2. Keuntungan maksimum yang diperoleh dari hasil optimasi melalui program linier ialah sebesar Rp 1.527.060.000. Hasil tersebut diperoleh dari selisih keuntungan optimasi pada saat alternatif terpilih (November III) yaitu sebesar Rp 23.334.010.000 dikurangi dengan kondisi eksisting (Rp 21.806.950.000).

\section{Daftar Pustaka}

[1] Yulianri ricky. 2014. Optimasi Alokasi Air untuk Irigasi Dengan Menggunakan Program linier. Skripsi. Bengkulu: Unuversitas Bengkulu.

[2] Nurnawaty. 2009. Optimasi Penggunaan Air Irigasi berbasis Pola Tanam pada Daerah Irigasi Kanjiro Kab. Luwu Utara Menggunakan Program Linear. Skripsi. Makassar: Universitas Makassar.

[3] Sosrodarsono, Suyono. 1985. Hidrologi Untuk Pengairan edisi 5. Jakarta: PT. Pradnya Paramita.

[4] Subagyo, Pangestu. 2010. Statiska Terapan. BPFE. Yogyakarta.

[5] Suhardjono. 1994. Kebutuhan Air Tanaman, ITN, Malang.

[6] Rispiningtati (2008). Model Optimasi Linier Teknik Sumberdaya Air. Tirta Media. Malang.

[7] Ma'ruf, Muhammad Imam. 2019. Analisis Pendapatan Dan Kelayakan Usahatani Padi Di Kecamatan Pitu Riawa Kabupaten Sidrap. Skripsi. Makassar: Universitas Makassar.

[8] Hasa, sabir. 2018. Analisis Pendapatan Usahatani Padi Sawah Di Desa Leppangan Kecamatan Pitu Riase Kabupaten Sidrap. Skripsi. Makassar: Universitas Makassar.

[9] Prasetyo, Adinur dan Kurniawan Prasetyo. 2009. Panduan Program Aplikasi QM for Windows Versi 3.0. Jakarta: Elex Media Komputindo.

[10] Miftahurrahman, 2006.Studi Optimasi Distribusi Air Pada Daerah Irigasi Rejoagung II Kabupaten Jombang Dengan Program Linier.Skripsi. Malang: Jurusan Teknik Pengairan, Fakultas Teknik, Universitas Brawijaya 